\title{
GESTÃO DO CONHECIMENTO APLICADA AS PRÁTICAS AMBIENTAIS
}

\section{lara Aparecida dos Santos Oliveira ${ }^{1}$}

\section{Cristiana Aparecida Portero Yafushi ${ }^{2}$}

\author{
Tatiene Martins Coelho ${ }^{3}$
}

\begin{abstract}
RESUMO: Com o objetivo de analisar como a gestão do conhecimento contribui para que as diversas práticas de preservação ambiental possam ser aplicadas na organização empresarial, o presente trabalho aborda a educação ambiental como ferramenta de transmissão das informações sobre o assunto em todos os níveis organizacionais e principalmente no setor produtivo, pois é o principal explorador de recursos naturais. Atualmente as questões ambientais são foco de pesquisa em todo mundo, onde são estudadas formas de atuação para sua preservação. As empresas devem atentar a este fato, pois os atuais consumidores estão a cada dia mais preocupados com a composição dos produtos e optam por organizações socialmente responsáveis. Além de aumentar a competitividade no mercado, a gestão ambiental também proporciona muitos benefícios às empresas que aderem o modelo em suas práticas organizacionais.
\end{abstract}

Palavras-chave: Meio ambiente. Gestão do conhecimento. Práticas sustentáveis.

\footnotetext{
${ }^{1}$ Aluna do curso e pós-graduação em auditoria, controladoria e finanças das Faculdades Integradas e Bauru -FIB. lara_ap_oli@yahoo.com.br.

${ }^{2}$ Aluna do curso e pós-graduação em gestão de pessoas e gestão da informação das Faculdades Integradas e Bauru - FIB. cristianayafushi@gmail.com.

${ }^{3}$ Professora Ms. dos cursos de administração e turismo das Faculdades Integradas de Bauru - FIB. tatyene@terra.com.br.
} 


\section{INTRODUÇÃO}

As questões ambientais atualmente se tornaram foco de discussão nos mais variados níveis da sociedade. São pesquisadas formas de contribuição para a preservação ambiental nos âmbitos municipais, estaduais, nacionais e até mesmo internacionais.

Muitas são as informações expostas em todos os lugares que se passa. Porém muito do que se estuda não é colocado em prática, o que faz com que a degradação do meio ambiente continue a crescer. A informação atualmente disseminada nos meios de comunicações é de acesso rápido, trazendo à sociedade uma dependência de computadores e internet, onde obtém a informação digital (VALENTIM, 2010).

Essas informações devem se transmitidas para mostrar à sociedade o quanto é importante a preservação da qualidade do meio ambiente para proporcionar a existência humana futura. De acordo com Valentim (2002), a economia de um país é resultado das informações que a sociedade dispõe por meio da comunicação, o conhecimento adquirido e divulgado está relativamente inter-relacionado com os diferentes segmentos econômicos dentro desse processo econômico e social produtivo e inovador.

Sendo assim todos os segmentos da sociedade, principalmente as empresas são responsáveis pela transmissão das informações às pessoas.

O conhecimento surge como a aplicação das informações adquiridas pelos seres humanos dentro de uma organização, onde todos adquirem ao mesmo tempo o direito e o dever de buscar as informações relacionadas à preservação do meio ambiente com o objetivo de torná-las em conhecimento a ser aplicado. Tais práticas são maneiras de agir para contribuir com o meio ambiente, orientando o individuo a aplicá-las na empresa e fora dela. Promover a aprendizagem organizacional, direcionando para a capacitação e autodesenvolvimento dos profissionais, segundo Teixeira Filho (2000), torna uma empresa capaz de dominar o conhecimento e tornar-se mais competitiva.

A gestão do conhecimento existe para garantir que as práticas sustentáveis serão efetuadas de acordo com todas as informações transmitidas às pessoas e empresas. Para Dias; Belluzzo (2003), a adequada capacitação do profissional, na 
utilização de modernas e eficazes ferramentas que agreguem valor à informação e novas abordagens de gerenciamento, favorecerão a oferta de informações e o compartilhamento do conhecimento contido nas mais variadas fontes.

No âmbito organizacional, além de contribuir para a preservação ambiental, as empresas também adquirem muitos benefícios econômicos, sociais, políticos e produtivos, aumentando assim sua competitividade no mercado em que estão inseridas. De acordo com Dias (2009), a gestão ambiental tem adquirido cada vez mais importância para a competitividade devido aos benefícios que causa ao processo produtivo, uma vez que proporciona melhor desempenho ambiental devido ao cumprimento das exigências normativas, possibilita maior inserção num mercado cada vez mais exigente em termos ecológicos e melhora sua imagem junto aos clientes e a comunidade.

O objetivo é estudar como a gestão do conhecimento nas organizações pode contribuir na transmissão das informações inerentes as práticas sustentáveis, demonstrando quais benefícios proporcionam as empresas que a aderem.

O trabalho foi realizado com base em pesquisas bibliográficas, tendo como fonte de dados, material de acervo literário e eletrônico. Segundo Cervo; Bervian (2002), a pesquisa bibliográfica tem como objetivo explicar um problema segundo a opinião de outros autores, buscando conhecer e analisar as contribuições culturais ou científicas publicadas anteriormente, proporcionando domínio sobre determinado assunto, tema ou problema por meio da metodologia científica.

\section{GESTÃO DO CONHECIMENTO APLICADA AS PRÁTICAS SUSENTÁVEIS}

\subsection{Gestão do conhecimento}

Segundo Lacombe (2003), conhecimento é a mistura de experiência estruturada, valores, informações contextuais e discernimento técnico que proporciona uma referência para avaliar e incorporar novas experiências e informações. Podendo ser conhecido também como o conteúdo agregado do pensamento humano, percepção e manipulação inteligente das informações. É adquirido por meio de informações obtidas em dados. 
Dados são registros físicos ou fatos armazenados em memória de computadores, as informações geradas por todo o processo de compilamento, coleta, disposição, organização e relevância dessas informações resultam em conhecimento (BEAL, 2004).

Fleury; Oliveira Júnior (2001), afirmam que o conhecimento é gerado através das interações que decorrem no ambiente de negócios e são desenvolvidas por meio de processos de aprendizagem, podendo também ser entendido como informação associada à experiência, intuições e valores.

Segundo Lacombe (2003), gestão do conhecimento é um conjunto de esforços ordenados e sistematizados visando a criação de um novo conhecimento, deve ser protegido contra o uso indevido.

Valentim (2006) define gestão do conhecimento como um conjunto de estratégias para criar/construir, adquirir/aprender, compartilhar/socializar e usar/utilizar ativos de conhecimento, para aplicação de métodos, técnicas, instrumentos e ferramentas que apóiam esse conjunto de estratégias.

Ainda segundo Valentim (2006), o conhecimento coletivo e o conhecimento individual são realizados por meio da interação do sistema e da própria organização, no entanto a complexidade das ações despendidas é diferente, pois em gestão da informação trabalha-se o conhecimento explícito que é a informação, já a gestão do conhecimento trabalha o conhecimento implícito que é o próprio conhecimento.

A gestão do conhecimento é responsável pela aplicação de métodos, técnicas e instrumentos, que objetiva a criação de uma cultura nas pessoas, voltada a explicitação do conhecimento, atua junto com os fluxos informais e tem foco no capital intelectual ou capital humano existente (VALENTIM, 2006).

As ações de combate a poluição somente começaram a partir da Revolução Industrial, embora desde a Antiguidade diversas experiências houvessem sido realizadas. (BARBIERI, 2007).

A era industrial, segundo Barbieri (2007), possibilitou o uso de técnicas produtivas intensivas em material e energia para atender mercados de grandes dimensões, fazendo com que a exploração de recursos e descarga de resíduos crescesse de maneira a ameaçar a subsistência de muitos povos atuais e futuros. Dessa forma, a 
maneira de produção e consumo exige recursos e gera resíduos em quantidades numerosas que já ameaçam a capacidade que o planeta suporta.

Alguns sinais que provam esse fato são: a perda da biodiversidade, a redução da camada de ozônio, a contaminação das águas, as mudanças climáticas em razão da intensificação do efeito estufa e outros que comprometem o futuro da terra e de todos os seres vivos (BARBIERI, 2007).

De acordo com Barbieri (2007), as informações sobre as conseqüências das contaminações divulgadas pela imprensa têm contribuído nestas últimas décadas que foram ricas em denúncias e debates sobre problemas ambientais encontrados por pesquisadores dos mais variados campos do conhecimento.

Segundo Seiffert (2009), todos esses problemas levaram o ser humano a reavaliar sua postura diante da utilização dos recursos naturais, que se concretizou por meio de diversos eventos com a participação de especialistas da área ambiental, buscando melhorias do controle do meio ambiente, propondo soluções, analisando o atual modelo e visando a sustentabilidade.

A tendência atualmente, segundo Barbieri (2007) é que a quantidade de pessoas preocupadas com o meio ambiente cresça à medida que elas se dêem conta de que os danos não afetam somente a qualidade de vida atual, mas também a sobrevivência da própria humanidade.

A disseminação dos conceitos de Garantia da Qualidade e Responsabilidade Social fez com que a gestão ambiental passasse a ocupar uma posição de destaque entre as funções organizacionais devido a contribuição positiva que proporciona à imagem da empresa e pelos efeitos danosos que um mau procedimento ambiental pode causar à integridade dela (VALLE, 2002).

\subsection{A importância da educação ambiental}

De acordo com Dias (2000), educação ambiental é o desenvolvimento do conhecimento, compreensão, habilidades e da motivação para adquirir valores, mentalidades e atitudes necessários para lidar com questões ou problemas ambientais, encontrando soluções sustentáveis. 
Meadows (1989 apud DIAS, 2000), conceitua educação ambiental como:

- Aprendizagem sobre como gerenciar e melhorar as relações entre a sociedade humana e o ambiente, de modo integrado e sustentável;

- A preparação de pessoas para sua vida enquanto membros da biosfera;

- O emprego de novas tecnologias, aumentando a produtividade, evitando desastres ambientais, minimizando os danos existentes, o conhecimento e utilização de novas oportunidades e tomada de decisões acertadas;

- Compreender, apreciar, saber lidar e manter os sistemas ambientais na sua totalidade;

- Aprender a analisar um problema global: sua historia, valores, percepções, fatores econômicos e tecnológicos, os processos naturais ou artificiais que o causaram e quais ações são sugeridas para saná-lo.

Segundo Dias (2009), dentre todas as espécies, o ser humano é a que possui maior capacidade de adaptação ao ambiente natural, podendo ser encontrado nas mais diversas localidades, como no deserto, no continente antártico, na floresta amazônica, sob o oceano, voando na atmosfera e além dela. Devido às modificações que ele mesmo causa no seu ambiente, torna-o diferente do natural.

A consciência da necessidade de utilizar poupadamente os recursos naturais, uma vez que eles podem se esgotar rapidamente mobiliza a sociedade no sentido de se organizar para que o crescimento econômico não seja predatório, mas sim sustentável (SEIFFERT, 2009).

Nesse sentido, para Seiffert (2009), é preciso criar condições socioeconômicas, institucionais e culturais que estimulem um rápido processo tecnológico poupador de recursos naturais e também uma mudança em direção a padrões de consumo que não limitem o uso de recursos per capta.

De acordo com Seiffert (2009), é importante repensar a forma de organização da sociedade, o uso qualitativo e quantitativo que ela faz de seus recursos naturais e as conseqüências da ação dos agentes econômicos. Isso implica em estudos sociais ambientais e suas inter-relações.

Assim será possível dar apoio as reflexões, análise, síntese, buscando soluções e estratégias de curto, médio e longo prazo para este contexto, viabilizando 
cientificamente um futuro mais próspero economicamente, justo e harmonioso (SEIFFERT, 2009).

\subsection{Práticas sustentáveis}

De acordo com Miller (2008) os seis passos para minimizar a utilização de recursos, resíduos e poluição também denominados seis passos para a sustentabilidade são:

1. Consumir menos - antes de adquirir qualquer produto, é preciso avaliar se é necessário ou se trata simplesmente de um desejo, se pode ser segunda linha (reaproveitado), ou ainda se tem possibilidade de ser emprestado ou alugado (reutilizado).

2. Reprojetar processos de fabricação e produtos para menor utilização de materiais e energia - deve-se buscar otimizar os projetos atuais buscando a melhoria contínua, como ocorreu com o peso dos automóveis que foram reduzidos em um quarto, substituindo várias itens de aço por plástico.

3. Reprojetar processos de fabricação com o intuito de produzirem menos resíduos e menos poluição - a maioria dos solventes orgânicos tóxicos podem ser reciclados ou trocados por outros à base de água ou de cítricos.

4. Desenvolver produtos fáceis de reparar, reutilizar, remanufaturar, compostar ou reciclar - produzir peças que podem ser facilmente reutilizadas ou recicladas proporciona uma grande economia para uma empresa de manufatura.

5. Reprojetar os produtos que tenham uma maior durabilidade - é o caso dos pneus, que segundo pesquisadores, seu tempo de vida que está em torno de 97 mil quilômetros poderá ser estendido para até 160 mil quilômetros.

6. Eliminar ou minimizar o uso de embalagens - em termos de questões ambientais a hierarquia seria preferencialmente nessa seqüência: a inexistência de embalagens, embalagem mínima e embalagem reciclável.

Além desses itens, outro método muito utilizado por várias empresas é o reaproveitamento. As formas mais comuns de reaproveitamento referem-se à 
recuperação de peças automotivas concentradas em ferros-velhos, tijolos, portas, madeiramento e outros itens residenciais (MILLER, 2008).

Nas sociedades atuais de alta produção, é cada vez mais comum a substituição de papéis descartáveis por reutilizáveis, bem como utensílios de plástico por pratos, copos e talheres reutilizáveis entre outros, segundo Miller (2008).

De acordo com Krugliankas et al. (2009), algumas práticas responsáveis na produção de bens e produtos são:

1. Adequação ás certificações ambientais: as certificações demonstram a existência de um comprometimento de todos os envolvidos quanto à adequação das normas, buscando eliminar ou minimizar agressões ao meio ambiente, nos quais se obtém selos ecológicos que potencializam a imagem da empresa em razão do cumprimento de padrões ambientais.

2. Atendimento á legislação ambiental: atender a legislação ambiental proporciona benefícios como: reconhecimento do poder público, da sociedade, melhora da imagem da empresa, melhora das relações comerciais e redução do risco de multas e indenizações com processos judiciais.

\section{Equipamentos que substituem a fonte de energia reduzem ou otimizam}

o consumo: as empresas estão buscando formas de reduzir seus custos operacionais, necessitando ser mais eficientes no uso e consumo de energia. A utilização de equipamentos que operam com fonte de energia renovável como a solar, eólica, resíduos orgânicos, biomassa ou hidrogênio é fundamental para combater as mudanças climáticas e minimizar a vulnerabilidade da empresa diante do preço e da obtenção de recursos.

4. Educação ambiental de funcionários e sociedade: estabelecer boas práticas de responsabilidade social em conjunto de parceiros internos e externos melhora a imagem socioambiental perante a comunidade local, contribuindo para o desenvolvimento de lideranças que atuem como agentes mobilizadores.

5. Destinação adequada de produtos pós - consumo: um local para tratamento representa um comprometimento com 0 meio ambiente. 
Determinados materiais como o papelão ondulado, plástico e lata de alumínio podem ser utilizados em caldeiras, proporcionando economia de combustível.

Temos como exemplo a Embraco, fabricante de compressores que retira do mercado produtos que encerraram seu ciclo de vida, no qual $60 \%$ dos produtos vendidos retornam para a empresa, sendo que em seis anos, ela retirou 884 mil compressores, reciclando 5 mil toneladas de aço e 2 mil toneladas de ferro fundido.

6. Redução de resíduos e emissões: devido a exigência da legislação e temor de serem multadas e terem que pagar indenizações, as empresas estão cada vez mais preocupadas com a gestão de seus resíduos, oriundos da produção industrial. Situação que leva as organizações a adotarem estratégias de recuperação, reutilização ou reciclagem de resíduos, que por sua vez contribui para reduzir os custos com recursos.

7. Uso de matéria prima reciclada: a utilização de materiais reciclados reduz o consumo de materiais oriundos da natureza e a quantidade de resíduos despejados em aterros sanitários, minimizando a extração de matéria-prima. A produção de uma tonelada de papel reciclado evita o corte de 30 árvores, economiza $98 \%$ de água e $80 \%$ de energia elétrica.

8. Estação de tratamento e reuso de água: a carência de água potável está impactando em proporções cada vez maiores nos custos operacionais das empresas, devendo ser levados em conta três aspectos para o seu uso eficiente - Definir as atividades de uso de água nobre e as passíveis de água de reuso; - Racionalizar o uso da água nos processos produtivos utilizando-se de procedimentos padronizados; - Conscientizar todos os envolvidos por meio de treinamentos.

9. Armazenamento adequado de resíduos e produtos tóxicos: o derramamento de materiais perigosos está atrelado à armazenagem que merece uma atenção especial dos gestores, pois além de causar danos na reputação da empresa, acarretará em pesadas multas pelo descumprimento da legislação. 
10. Seleção de fornecedores locais com boa conduta ambiental: caso os fornecedores não atendam aos padrões socioambientais, a empresa compradora poderá ser responsabilizada e acionada pela justiça. Por essa razão deve-se escolher fornecedores atentos com a questão ambiental, promovendo assim o surgimento de novos modelos, crescimento do negócio e melhoria em toda cadeia de fornecedores.

Segundo Krugliankas et al. (2009), a produção sustentável envolve diversas medidas de boas práticas em seu processo. Tendo em vista a necessidade de avaliar esse modelo de produção, algumas empresas utilizam indicadores de desempenho ambientais, o sistema de indicadores ambientais apresentado pela Global Reporting Iniciative (GRI) é dividido em:

1. Uso de materiais: relacionado ao tipo e quantidade de materiais utilizados, eficiência produtiva e custos de produção.

2. Consumo de energia: relacionado às quantidades e tipos de energia utilizada e gerada.

3. Consumo de água: volume extraído por fonte reciclada e reutilizada.

4. Biodiversidade: área de terra protegida, produtiva e restaurada, grau de risco de extinção e método administrativo.

5. Emissão de poluentes: refere-se às quantidades e tipos de efluentes lançados no ar, água e solo.

6. Produtos e serviços gerados: avaliam as quantidades e características dos produtos finais, armazenamento e transporte.

7. Conformidade: multas e sanções pelo não cumprimento da legislação ambiental.

8. Transporte: impactos ambientais do deslocamento de produtos, bens e materiais utilizados pela empresa bem como os trabalhadores.

9. Geral: investimentos realizados para manutenção e proteção ambiental.

De acordo com Valle (2002), ações que podem reduzir os riscos ambientais são:

1. Auditorias periódicas: permitem revisar as áreas e operações de maior risco, identificar desvios nos procedimentos de emergência e antecipar-se à 
ocorrência de danos, constituindo uma etapa obrigatória para a certificação pela norma ISO 14001;

2. Tratamento adequado de resíduos gerados: corresponde à eliminação através da neutralização ou reciclagem dos elementos tóxicos, pois a simples disposição dos resíduos em aterros sanitários não elimina o risco ambiental, mas constitui um passivo ambiental permanente para a empresa geradora;

3. Identificação e quantificação de passivos ambientais: que possam existir ou serem potenciais nas áreas ocupadas pela organização;

4. Adoção de tecnologias limpas (cleaner production - produção mais limpa): que eliminam ou reduzem a geração de poluentes no processo produtivo;

Uma prática muito conhecida e utilizada atualmente pelas pessoas e empresas é a reciclagem. De acordo com Miller (2008), reciclar consiste na transformação de materiais sólidos descartáveis em produtos novos úteis. Residências e empresas produzem cinco tipos principais de materiais recicláveis, são eles: papel, vidro, alumínio, aço e alguns tipos de plástico.

Os materiais coletados são encaminhados para reciclagem primária e secundária. Na primária ocorre a transformação dos resíduos em produtos do mesmo tipo. Já a secundária, por sua vez refere-se à conversão dos resíduos em produtos diferentes, por exemplo, a borracha de um pneu pode ser fragmentada e servir de revestimento para estradas, segundo Miller (2008).

De acordo com Miller (2008), outro método que deve ser utilizado pela população e empresas é o de separação na fonte que consiste em separar os lixos por categorias de materiais recicláveis como, vidro, papel, metais e determinados tipos de plásticos e materiais compostáveis. Esse método apresenta várias vantagens em relação ao anterior, proporcionando menor poluição do ar e da água, baixo custo de inicialização e custos moderados de operação, economia de energia, geração de empregos, fornecimento de materiais mais limpos e puros, além de educar as pessoas quanto à necessidade de reduzir, reaproveitar e reciclar os resíduos.

Para incentivar a reciclagem e o reaproveitamento, de acordo com Miller (2008) deve-se inicialmente igualar as condições econômicas, maximizando os subsídios e os 
descontos fiscais e minimizando esses benefícios para a produção de materiais com recursos virgens. Utilizam-se também de várias outras estratégias como: pagar pelo seu lixo, incentivar ou exigir compras do governo para aumentar a demanda e conseqüentemente diminuir os preços.

Outros instrumentos também são: apoio ao desenvolvimento científico e tecnológico, educação ambiental, unidades de conservação e informações ao público (BARBIERI, 2007).

\subsection{Vantagens para as empresas que aderem as práticas ambientais}

Conforme Krugliankas et al. (2009), a preocupação com o meio ambiente está formando um novo paradigma para a gestão de negócios, forçando as empresas a apresentarem ações e soluções socialmente corretas, ambientalmente sustentáveis e economicamente viáveis.

Para Dias (2009), uma empresa se integra às questões ambientais por adquirir estímulos interno e externos. Alguns estímulos internos são:

1. Necessidade de redução de custos: através da redução de aquisição de material por unidade produzida e com o uso eficiente de energia, água e materiais auxiliares no processo produtivo, a empresa obtém benefícios financeiros imediatos, reduzindo também desperdícios e resíduos perigosos.

2. Incremento na qualidade do produto: a elevação da qualidade do produto é obtida através do alto nível na qualidade ambiental devido aos fatores de funcionalidade, confiabilidade, durabilidade e maior facilidade para manutenção.

3. Melhoria da imagem do produto e da empresa: um produto quando desenvolvido por uma empresa reconhecida ambientalmente terá uma imagem positiva junto aos clientes, que poderá ser fortalecida pelas normas que agreguem um selo de qualidade ambiental a ele.

4. Necessidade de inovação: para buscar diferenciação diante dos consumidores ou para manter-se no mercado com vantagem competitiva, onde um produto poderá atingir patamares de oportunidades nunca vistos. 
5. Aumento da responsabilidade social: inclui a preocupação com a diversidade, com as gerações futuras e com os efeitos do processo produtivo na comunidade local, possibilitando a implantação de um Sistema de Gestão Ambiental (SGA).

6. Sensibilização do pessoal interno: o pessoal interno das empresas pode constituir uma opinião pública, influenciando o quadro de gestores a adotarem medidas corretivas ou proativas em relação ao meio ambiente interno e externo.

Segundo Dias (2009), alguns estímulos externos são:

1. Demanda de mercado: devido ao crescente aumento das exigências ambientais por parte de clientes e consumidores, as empresas se vêem obrigadas a melhorar sua forma de atuar, modificando assim seus processos e produtos.

2. O poder público e a legislação ambiental: as empresas necessitam conhecer a legislação atual e prever a legislação futura de seus países e daqueles para os quais exportam.

3. O meio sociocultural: a pressão do meio social é exercida pelos consumidores e sociedade como um todo que colocam exigências sobre os produtos e os processos de produção.

4. As certificações ambientais: os selos ecológicos são identificações emitidas por entidades, organizações comerciais ou não governamentais para reconhecer que o produto cumpriu com padrões ambientais previamente estabelecidos.

Esse direcionamento, de acordo com Krugliankas et al. (2009), propicia diferentes oportunidades de negócios, promove uma imagem empresarial positiva perante a sociedade, além de atrelar a questão ambiental com a econômica, quebrando o paradigma de que ela representa custos para a empresa. Os benefícios também são refletidos para os funcionários e para terceiros à medida que proporciona um ambiente de trabalho mais seguro através do estabelecimento da educação ambiental, utilização de equipamentos de proteção individual e redução de acidentes. 


\section{CONSIDERAÇÕES FINAIS}

A informação e o conhecimento podem ser recursos aplicados à educação ambiental, ou seja, podem ser desenvolvidos pela gestão do conhecimento (GC).

A oferta de informação e o compartilhamento do conhecimento proporcionam condições para que as práticas sustentáveis sejam disseminadas e praticadas.

A adesão organizacional as práticas ambientais, contribui com benefícios econômicos, sociais, políticos e produtivos e cada vez mais torna-se importante para a competitividade devido aos benefícios relacionados aos resíduos gerados no processo produtivo.

Por se tratar de uma pesquisa bibliográfica, existe uma limitação de ensaios que comprovem a eficiência da aplicação prática, no entanto, é possível contribuir com um estudo empírico que demonstra como a gestão do conhecimento nas organizações pode contribuir na disseminação das informações das práticas sustentáveis, demonstrando os benefícios proporcionados no ambiente empresarial.

\section{REFERÊNCIAS}

BARBIERI, J. C. Gestão ambiental: conceitos modelos e instrumentos. 2. ed. São Paulo: Saraiva, 2007.

BEAL, A. Gestão estratégica da informação: como transformar a informação e a tecnologia da informação em fatores de crescimento e de alto desempenho nas organizações. São Paulo: Atlas, 2004.

CERVO, A. L.; BERVIAN, A. Metodologia científica. 5. ed. São Paulo: Prentice Hall, 2002.

DIAS, G.F. Educação ambiental: princípios e práticas. 6 ed. São Paulo: Gaia, 2000.

DIAS, M.M.K; BELLUZZO, R.C.B. Gestão da informação em ciência e tecnologia sob a ótica do cliente. Bauru: EDUSC, 2003.

DIAS, R. Gestão ambiental: responsabilidade social e sustentabilidade. São Paulo: Atlas, 2009.

FLEURY, M.T.L.; OLIVEIRA JUNIOR, M.M. Gestão estratégica do conhecimento: integrando aprendizagem conhecimento e competências. São Paulo: Atlas, 2001. 
KRUGLIANKAS, I. A. et al. Gestão socioambiental: Responsabilidade e sustentabilidade do negócio. São Paulo: Atlas, 2009.

LACOMBE, F.J.M. Administração: princípios e tendências. São Paulo: Saraiva, 2003.

MILLER, G. T. Ciência ambiental. São Paulo: Cengage Leatning, 2008.

SEIFFERT, M. E. B. Gestão ambiental: instrumentos, esferas de ação e educação ambiental. São Paulo: Atlas, 2009.

TEIXEIRA FILHO, J. Gerenciando conhecimento: como a empresa pode usar a memória organizacional e a inteligência competitiva no desenvolvimento de negócios. Rio de Janeiro: SENAC, 2000.

VALENTIM, M.L.P. Inteligência competitiva em organizações: dado, informação e conhecimento. Datagramazero, Rio de Janeiro, v.3, n.4 ago.2002 art.2. Disponível em:http://www.dgz.org.br/ago02/Art 02.htm. Acesso em: 28 jun.2012.

VALENTIM, M.L.P. Informação, conhecimento e inteligência organizacional. 2. ed. São Paulo: Fundepe, 2006.

VALENTIM, M.L.P. Gestão, mediação e uso da informação. São Paulo:Cultura Acadêmica, 2010. E-books. Disponível em:

<http://www.culturaacademica.com.br/img/arquivos/Gestao_mediacao_e_uso_da_inform acao.pdf>Acesso em: 28 jun. 2012.

VALLE, C. E. Qualidade ambiental: ISSO 14000. 4. ed. São Paulo: SENAC, 2002. 